


\title{
Llevar La palabra. Un análisis de la relación entre las iglesias y la escolarización de niños indígenas tobas/qom y mbya-guarani de Argentina $^{1}$
}

\author{
Noelia Enriz ${ }^{2}$ \\ CONICET, Universidad de Buenos Aires, Argentina \\ noelia.enriz@gmail.com \\ Mariana Garcia Palacios ${ }^{3}$ \\ CONICET, Universidad de Buenos Aires, Argentina \\ mariana.garciapalacios@gmail.com \\ Ana Carolina Hecht ${ }^{4}$ \\ CONICET, Universidad de Buenos Aires, Argentina \\ anacarolinahecht@yahoo.com.ar \\ Recibido: 4 de febrero de 2016 \\ Aceptado: 22 de julio de 2016 \\ Disponible en línea: 20 de diciembre de 2016
}

1 El presente manuscrito recupera una investigación documental y etnográfica con poblaciones indígenas de Argentina.

2 Doctora en Antropología, Universidad de Buenos Aires (UBA) (Argentina). Docente, Departamento de Ciencias Antropológicas, FFyL. UBA. Investigadora Asistente del CONICET (Buenos Aires, Argentina).

3 Doctora en Antropología, UBA (Argentina). Docente, Departamento de Ciencias Antropológicas, FFyL, UBA. Becaria Postdoctoral, Fondation Maison des sciences de l'homme (FMSH), 2015 (Francia). Recientemente, ha ingresado a la Carrera de Investigación de CONICET (Buenos Aires, Argentina).

4 Doctora en Antropología, UBA (Argentina). Docente, Departamento de Ciencias Antropológicas, FFyL, UBA. Investigadora Asistente del CONICET (Buenos Aires, Argentina). 


\title{
Llevar La palabra. Un análisis de la relación entre las iglesias y la escolarización de niños indigenas tobas/qom y mbya-guarani de Argentina
}

\section{Resumen}

Históricamente, la relación entre los grupos indígenas y el Estado argentino ha sido compleja. En el marco de un modelo de escolarización estatal que no recuperó los conocimientos y experiencias de las poblaciones indigenas, diversas iglesias persiguieron objetivos propios, y reemplazaron, cuestionaron y apoyaron tareas del Estado. Aquí analizaremos los vínculos entre las iglesias (católica y evangélicas) y las poblaciones indigenas, centrándonos en los ámbitos educativos y, especialmente, en el proceso de alfabetización. Sistematizaremos aquellas acciones que, con propósitos diversos, pretendieron acercar a los pueblos tobas/ qom y mbyá-guaraní (norte y noroeste de Argentina) al uso oral de la lengua oficial del Estado y a su escritura, así como al desarrollo de la escritura de las lenguas indígenas. En muchos casos y aún con contradicciones, estas acciones representan un antecedente de la educación escolar intercultural poco estudiado. Metodológicamente, se recuperarán fuentes documentales y análisis teóricos, a la luz de exploraciones de campo etnográficas realizadas en la última década con dichas poblaciones.

Palabras clave: indigenas; educación; Estado; iglesias; Argentina

\section{Carrying The Word. An Analysis of the Relationship between Churches and the Schooling of Tobas/qom and Mbya-Guarani Indigenous Children in Argentina}

\begin{abstract}
The relationship between indigenous groups and the Argentine state has been complex throughout history. In the framework of a state schooling model that did not recover the knowledge and experience of indigenous peoples, various churches defended their own interests, and replaced, challenged and supported State's tasks. This paper discusses the links between the (Catholic and Protestant) churches and indigenous peoples, focusing on education, particularly on literacy process. We systematize actions that, for various purposes, sought to promote the oral and written use of the official state language by the tobas/qom and mbyaguarani people (northern and northwestern Argentina), as well as facilitate the development of the writing of indigenous languages. In many cases and even with contradictions, these actions represent an understudied precedent of intercultural school education. Methodologically, documentary sources and theoretical analyzes are recovered in light of ethnographic field explorations made in the last decade with those populations.
\end{abstract}

Keywords: indigenous people; education; State; churches; Argentina

\section{Levar Palabra. Análise do relacionamento entre igrejas e escolarização de crianças indigenas tobas/qom e mbya-guaraní na Argentina}

\section{Resumo}

Historicamente, o relacionamento entre turmas indígenas e o Estado argentino tem sido complexo. No quadro de um modelo de escolarização estatal que não recuperou os conhecimentos e experiências dos povos indigenas, diferentes igrejas perseguiram objetivos próprios e substituíram, questionaram e apojaram tarefas do Estado. Aqui vamos analisar as ligações entre igrejas (católica e evangélicas) e os povos indígenas, nos focando nos âmbitos educativos e, especialmente, no processo de alfabetização. Sistematizaremos aquelas ações que, para vários fins, pretenderam se aproximar dos povos tobas/qom e mbyá-guaraní (norte e noroeste da Argentina) ao uso oral da lingua oficial do Estado e sua escrita, bem como ao desenvolvimento da escrita das línguas indigenas. Em muito caso e mesmo com contradições, aquelas ações representam um antecedente do ensino escolar intercultural pouco estudado. Metodologicamente, foram recuperadas fontes documentais e análises teóricas, à luz de explorações de campo etnográficas realizadas na última década com tais povos.

Palavras-chave: indigenas; ensino; Estado; igrejas; Argentina 


\section{Introducción}

Argentina es un país caracterizado por una amplia diversidad poblacional $l^{5}$, y atravesado por grandes desigualdades, en términos materiales, simbólicos y políticos, que históricamente han producido y legitimado diferenciaciones también en materia educativa.

Por otro lado, un aspecto singular de la situación poblacional del país es, sin duda, el relato histórico canonizado respecto de la extinción de las poblaciones indígenas, paralelamente a la promoción de la presencia europea como un elemento de transformación de la matriz poblacional (Novaro, 2003). En este sentido, el correlato más obvio de este discurso es la inexistencia, hasta fines del siglo XX, de propuestas educativas que se abocaran a la población indígena, mientras se construía un sistema educativo nacional que ponía su énfasis en las poblaciones urbanas y periurbanas, cuya procedencia se asociaba más a la migración, especialmente a la europea.

Este texto pretende poner de manifiesto la relevancia del rol que ciertos actores han tenido en materia de politicas escolares y educativas dirigidas a aquellos sectores de la sociedad menos incluidos en las propuestas hegemónicas. Concretamente nos referimos al papel que han tenido diversas iglesias en la formación y alfabetización de poblaciones indigenas del norte argentino (Chaco y Misiones). Interpretamos estas tareas de las iglesias en términos de efectos de Estado (Trouillot, 2001), centralmente, por tratarse de instituciones transnacionales que se abocan a una tarea que se articula, aún conflictivamente, con los intereses del Estado.

Aquí, particularmente, recuperaremos fuentes documentales y estudios teóricos, sistematizados a la luz de las exploraciones de campo etnográficas con población mbya y toba/qom realizadas por las autoras $^{6}$. La actual situación de las poblaciones indígenas argentinas

\footnotetext{
Según datos aportados por el último censo nacional de población (INDEC, 2010), el 2,4\% de los argentinos se declara indígena o descendiente de algún pueblo originario, mientras que el $5 \%$ de los habitantes del territorio es nacido en el extranjero.

6 La Dra. Enriz realiza estudios etnográficos con la población mbya desde el año 2003, mientras que las doctoras García Palacios y Hecht trabajan con el pueblo toba/qom desde 2006 y 2002, respectivamente.
} 
es parte de un presente históricamente construido en el que intervinieron diversos agentes e instituciones. Con el fin de complejizar el rol que tienen y han tenido en estos procesos las distintas iglesias, nos hemos abocado al relevamiento documental, para acercarnos a la comprensión de la dimensión histórica de más largo plazo. Es decir que, entendiendo los escenarios actuales como parte de un "presente historizado" (Rockwell, 2009), nuestros trabajos de campo con diversas poblaciones indígenas han sido el puntapié para la lectura y sistematización de fuentes documentales. Con esta propuesta pretendemos romper con las miradas ahistóricas, casuísticas y fragmentarias con las que muchas veces se asocia a la antropologia (Achilli, 2013; Wolf, 2014). Consideramos, entonces, que este análisis permitirá complejizar los abordajes de los procesos contemporáneos, ampliar el rango histórico de la indagación y, a su vez, habilitar la posibilidad de cotejar similitudes y contrastes entre experiencias de estas dos poblaciones. En este sentido, es importante destacar que el contrapunto entre casos deviene interesante porque entre ellos se dieron procesos de evangelización diferentes: por un lado, entre los tobas/qom; luego de los contactos con la Iglesia católica, fueron ganando influencia diversas iglesias protestantes, que confluyeron en la conformación de un movimiento sociorreligioso indigena que fusiona elementos "tradicionales" qom con otros propios del evangelismo. Por otro lado, los mbya-guaraníes, habitantes de la región de mayor predominancia de expansión jesuita en América, quienes mantuvieron vínculos con la Iglesia católica hasta mediados del siglo XX, e incluso impactaron en los procesos de escolarización hasta la actualidad.

En medio de este contraste, queremos subrayar que los procesos de alfabetización indígena han perseguido intereses diversos, encarnados en las diferentes agencias que los abordaron. Problematizaremos, así, de qué modos las experiencias alfabetizadoras religiosas dan cuenta de la difusión de sus propios credos, utilizando la palabra escrita.

A continuación, realizaremos un breve recorrido por las relaciones históricas entre el Estado argentino y los pueblos indígenas, haciendo hincapié en las propuestas del sistema educativo escolar. Luego, nos detendremos en las acciones programáticas que la Iglesia católica, 
con sus diferentes órdenes, llevó a cabo a lo largo del territorio. Más adelante, analizaremos con mayor detalle los dos casos particulares: los contactos de los grupos toba/qom y mbya-guaraní con las diversas iglesias y sus corolarios en el campo educativo; en especial, el proceso de alfabetización y escritura de las lenguas nativas. Por último, tras abrevar en los nuevos desarrollos de la Educación Intercultural Bilingüe en el país, presentaremos las principales conclusiones a las que hemos arribado.

\section{Los pueblos indigenas, el Estado y la escolarización en Argentina}

Las poblaciones indígenas fueron contempladas como sujetos de la educación pública nacional argentina con reglamentaciones específicas recién a fines del siglo XX. Anteriormente, el modelo educativo decimonónico generó una propuesta homogeneizadora, para población urbana o periurbana, centrada en la incorporación al conocimiento de la lengua, historia y geografia canónica. La pequeña porción de la población indígena que se sumó a dicho proceso, lo hizo sin que esto supusiera un cuestionamiento al modelo hegemónico, e invisibilizando sus lenguas, historias y saberes. Argentina lideró las propuestas escolares universalizadoras en la región, desarrollando, como parte de las políticas del Estado, modelos educativos de calidad muy tempranamente. Sin embargo, esta primera tendencia, desarrollada en el gobierno de Domingo Faustino Sarmiento, a mediados del siglo XIX, pretendia generar un sistema escolar homogeneizador que solo atendía a la incorporación de aquellos sectores de la sociedad que debían afianzar su vínculo con las particularidades de la nación. Si bien este esquema incluyó la presencia de escuelas en zonas rurales, mantuvo el mismo lineamiento de contenidos y materiales, excluyendo las particularidades del medio rural escolar (Puiggrós, 2006; Padawer et al., en prensa).

La propuesta homogeneizadora aspiraba a construir un escenario monolítico respecto de la lengua, historia y geografia hegemónicas. 
Las escuelas se poblaron de niños y niñas cuyas familias se encontraban en condiciones de acompañar el proceso escolarizador, porque contaban con los recursos simbólicos y materiales necesarios para ello, y porque podian prescindir, al menos en parte, de la participación económica que suponía el ingreso tardío de un hijo/a al mercado de trabajo. La porción de la población indígena que se sumó a la escolaridad en dicho proceso fue muy escasa, y permaneció invisibilizada, inmersa en un proceso de integración subalterna a un modelo europeizante y urbano.

Recién a finales del siglo XX, comenzaron los modelos de Educación Intercultural Bilingüe (en adelante, EIB), que tuvieron la intención de atender las experiencias de las poblaciones indígenas, pero como parte de políticas focalizadas que, haciendo un uso particular de la diversidad, muchas veces terminaron encubriendo las desigualdades socioeducativas (Neufeld y Thisted, 1999). Así, como señalamos en artículos anteriores (Hecht, 2007; Borton et al., 2010; García Palacios, Hecht y Enriz, 2015; Hecht et al., 2015), las propuestas escolarizadoras que consideran a la población indígena parecen alinearse en torno de dos tendencias: por un lado, encontramos las ligadas al asimilacionismo y, por otro, las particularistas. Consideramos que estas dos expresiones presentan en realidad un falso dilema entre una propuesta de inclusión asimilacionista y otra que expresa la exclusión segregadora (Borton et al., 2010). Se trata de una engañosa dicotomía entre un esfuerzo de inclusión de la diversidad que termina siendo asimilacionista y un rescate de la diversidad que, al folklorizarla y fijarla, termina generando segregación. Como desarrollaremos más ampliamente en el último apartado de este escrito, consideramos que es posible entender la interculturalidad de un modo que vaya más allá de estas opciones: un modelo intercultural en educación podría enriquecer a toda la sociedad si trascendiera la concepción de la diversidad centrada en algunos (la mirada focalizadora) e incorporara los aportes de los diversos grupos para universalizarlos a toda la población, superando el universalismo hegemónico. Este modelo necesariamente debería sopesar las desigualdades históricas y actuales que terminan por jerarquizar las posibles contribuciones culturales de los grupos que conforman el Estado. 
En resumidas cuentas, si bien desde 1994 la Constitución Nacional incluye a la EIB como un derecho de los pueblos indígenas, la interpretación que conlleva su implementación en diversas provincias ${ }^{7}$ la sitúa como un derecho de quienes se encuentran interpelados por su diversidad lingüistico-cultural y subsisten en condiciones de desigualdad socioeconómica. Este tardío y limitado reconocimiento a nivel nacional contrasta con la idea contemporánea de una nación pluriétnica y multilingüe. A nivel provincial encontramos intervenciones a favor de la diversidad más tempranas y más tardías, como desarrollaremos a continuación.

Las experiencias sistemáticas de EIB en la provincia de Chaco comenzaron después de la sanción de la Ley Provincial N 3258 "De las Comunidades Indígenas" en el año 1987. A partir de esa época y hasta la actualidad, puede caracterizarse a esta provincia como una de las más progresistas en cuanto al reconocimiento de los derechos indígenas en lo escolar, ya que se destaca una legislación que oficializa a las lenguas indígenas en la provincia y que postula la creación de las escuelas públicas de gestión social indígena.

En cambio, en Misiones, es recién durante la primera década del año 2000 que se dio inicio a un programa de educación bilingüe de frontera (básicamente con las escuelas lindantes con Brasil); unos años más tarde esta iniciativa se expandió para contemplar a las poblaciones indígenas locales mediante la incorporación de auxiliares bilingües (español-mbya guaraní) en las instituciones con matrícula indigena.

Sin embargo, como hemos anticipado, existieron propuestas no desarrolladas por el Estado, sino por otras instituciones (particularmente religiosas) respecto de la escolarización y alfabetización de estas poblaciones. Así, en la compleja relación entre los grupos indígenas y el Estado argentino, han intervenido también diversas iglesias que, persiguiendo objetivos propios, reemplazaron, intervinieron, cuestionaron y apoyaron tareas del Estado. Nos proponemos abordar

Argentina es una república federal, organizada en jurisdicciones territoriales denominadas provincias. Las provincias poseen una autonomía relativa para la implementación de políticas nacionales. 
especialmente esas primeras propuestas para, luego, sopesar su influencia en las iniciativas posteriores de la EIB.

\section{La Iglesia católica y las poblaciones indigenas}

La relación entre diversas iglesias y poblaciones indígenas de Argentina es de muy larga data. Desde el proceso de conquista y colonización española, la Iglesia católica fue la encargada de la "conversión" y "civilización" de muchos de los pueblos indigenas. Su presencia en el territorio con las actividades misionarias de sus diversas órdenes no se vio interrumpida desde la llegada española (Braunstein y Miller, 1999). Con la consolidación temprana de administraciones socioterritoriales se fue delineando un ámbito propicio para la conquista religiosa, que se desarrolló inicialmente a través de la creación de reducciones destinadas a "pacificar" y evangelizar a "los bárbaros". Posteriormente, la creación de ciudades ${ }^{8}$ daba cuenta de los roles administrativos y religiosos de forma explícita, ya que el esquema básico de estas suponía la delimitación de una plaza central, en torno a la cual se construían sedes administrativas e iglesias, generalmente católicas.

El proceso de consolidación de la Corona española en estas tierras implicó la necesidad de resolver diversos conflictos político-jurisdiccionales. Como en última instancia servía a estos intereses, desde sus inicios el proyecto evangelizador jesuita (Compañía de Jesús) contó con un amplio apoyo político, encarnado localmente en las figuras del gobernador Hernandarias y el obispo Ignacio de Loyola.

La Compañia de Jesús instaló misiones o "reducciones para indios" en Paraguay, en el sur de Brasil y en las provincias argentinas de Misiones y Corrientes. En el plano de lo cotidiano, en ellas el vínculo

8 En 1536, cuando Pedro de Mendoza fundó Buenos Aires, envió expediciones que debían remontar el río Paraná en busca de los reinos del Perú y sus fabulosas riquezas, conocidas como El Dorado. Uno de estos grupos llegó hasta el río Pilcomayo y fundó Asunción en Paraguay. En un primer momento, las relaciones con los guaraníes fueron buenas, pero rápidamente aumentó el abuso de los españoles, quienes convirtieron a los indígenas en mano de obra esclava. Como señala Roulet (1993), dicho abuso se fue incrementando paulatinamente, mediante la instalación de un sistema de encomiendas para realizar todo tipo de labores, como cuidar ganado, recolectar yerba mate desde la selva en grandes fardos a hombro o, en el caso de las mujeres, hilar y tejer (Enriz, 2011). 
con las poblaciones se desarrollaba mediante diferentes experiencias evangelizadoras que se inmiscuían en diversos ámbitos y actividades. A la creación de espacios normados para el trabajo, la educación y la vida doméstica, se adicionaba la incorporación de aspectos socioculturales de las propias poblaciones en las dinámicas jesuitas. De este modo, con el fin último de convertir a la población indígena a la religión católica, en las reducciones se estandarizó la lengua indígena, por ejemplo, el guaraní (Melià, 1968/1993; Wilde, 2009), para rezar oraciones católicas en las lenguas nativas.

En definitiva, las reducciones implicaban la concreción de modelos de organización social que se plasmaban en la transformación de las prácticas cotidianas de los sujetos que habitaban estas tierras. Podemos ver aquí los efectos de Estado del accionar de la Iglesia si tenemos en cuenta que esta transformación de las poblaciones de la mano de las misiones fue también capitalizada favorablemente por la Corona. Por ejemplo, en defensa de la frontera, la ocupación española organizó ejércitos con la población de las reducciones para enfrentar a los portugueses (Avellaneda y Quarleri, 2007). El primer gran triunfo contra los portugueses lo alcanzaron las milicias jesuitas en la batalla de Mbororé en 1641 con un ejército de guaraníes (Blanco, 1898, citado en Avellaneda y Quarleri, 2007).

En el plano educativo, como hemos mencionado, la formación en las reducciones se focalizaba en aspectos sociales, espirituales y morales con objetivos también políticos. Allí tenía gran incidencia la estandarización de la lengua sumada a la alfabetización, así como la educación de los cuerpos, para el trabajo rutinario y para el ejercicio controlado de la fuerza.

La tarea en las reducciones no era sencilla, especialmente en el trabajo con los adultos, por lo tanto, se recomendaba trabajar con los niños indígenas como una estrategia de acción sobre las familias.

La educación de los niños y su necesaria conversión religiosa era vista como una estrategia de cristianización de los grupos, convirtiendo a los niños en vehículos morales y espirituales de las familias 
(García Palacios, 2012). Para del Priore (1991), quien analiza el rol de los jesuitas en la colonia en Brasil, la infancia era percibida como un momento oportuno para la catequesis, porque se concebía como una época ideal para la renuncia a la "cultura autóctona" de los niños y niñas indígenas, ya que ciertas prácticas y valores no se habrian aún sedimentado en ellos y ellas, convirtiéndolos en un catecumenado privilegiado (García Palacios, 2012). En el mismo sentido, Díaz (2000) señala, respecto al caso de las reducciones jesuíticas de guaranies, que se elegían a los niños y niñas para que recibieran una educación esmerada y sirviesen de maestros de sus padres, apelando, así, a la cristianización "del indio por el indio".

Si bien los jesuitas fueron expulsados en la segunda mitad del siglo XVIII, durante el proceso de conformación del Estado nacional continúa el establecimiento de misiones católicas de diversas órdenes (salecianos, franciscanos, etc.) en distintas zonas del país (Padawer et al., en prensa). La promoción de la conversión religiosa se constituyó también en uno de los objetivos del Estado, en alianza con la Iglesia católica. Según Gordillo (2006), la Constitución de 1853 -la primera de carácter nacional-, situó a los pueblos indígenas fuera de la nación claramente: el Congreso debía "negociar tratados" con grupos indígenas y promover su "conversión al catolicismo".

Como ya hemos subrayado, el proceso de alfabetización no ha sido el único objeto perseguido por estas instituciones eclesiásticas, sino más bien un objetivo privilegiado por su vínculo con la futura evangelización. Así, la Iglesia católica se propuso desarrollar, sobre todo en los internados y colegios, una educación llamada "integral", que no se limitaría a una formación científica del currículo básico, sino que también incorporaría las dimensiones del espíritu y la moral (Esquivel, 2008; García Palacios, 2012). Generalmente, además, incluía una "capacitación laboral” (Szulc, 2009), y como señalamos anteriormente, la formación militar para la defensa de las fronteras. 


\section{En elChaco: las órdenes de la Iglesia católica, las iglesias protestantes y el movimiento indigena del Evangelio}

La región del Chaco presenta particularidades respecto del proceso de vinculación de los indigenas con las iglesias y especialmente respecto del proceso de alfabetización. Si bien los jesuitas en el siglo XVIII ya habían iniciado un proceso de conversión y educación "no formal" en el noreste, fueron miembros de la orden franciscana los que a mediados del siglo XIX se establecieron en misiones en la región del Chaco (Braunstein y Miller, 1999; Hirsch y Serrudo, 2010).

Las avanzadas militares fueron la estrategia desarrollada por el Estado para ampliar la frontera y las oportunidades para el desarrollo capitalista. Una vez que se amplia la frontera, comienza a desarrollarse la industrialización, que cuenta con la mano de obra indígena como herramienta a bajos costos. La incorporación de esta población a las industrias capitalistas se da mediante estrategias coercitivas y también misionales que trabajan para lograr la "pacificación" (Iñigo Carrera, 1993; Tamagno, 2001). A su vez, la inmigración europea coadyuva en el desarrollo de chacras y otro tipo de explotaciones de menor escala donde los indigenas también son necesarios.

De este modo, enmarcados en un proceso de masiva inmigración europea y cercamiento del territorio, los indigenas eran instados a acercarse a las lógicas hegemónicas del capital. Para ello, era necesario un proceso de transformación de las actividades cotidianas, que una propuesta evangelizadora podía encarar, tal como se desprende del apartado anterior, unificando formación académica, espiritual y para el trabajo (Wright, 2008).

Así, según Artieda y Rosso (2005), la escolarización de los indígenas en escuelas públicas comienza a desarrollarse a fines del siglo XIX con la creación de colonias y reducciones indígenas. En este periodo aparecen las escuelas públicas para los hijos de los indigenas que trabajaban en los ingenios azucareros (Giordano, 2004). Así, los sentidos construidos en torno a la educación para indígenas se centran en el disciplinamiento de los niños, con el fin de incorporarlos posteriormente 
en el sistema de trabajo (Artieda y Hecht, 2012), algo que también se dio en otros sectores de la sociedad en condiciones de desigualdad.

Si bien el patrón general de avance misional se mantuvo en otras órdenes y regiones del país, esto sucedió con matices en la región del Chaco, porque en ciertos territorios las irrupciones de iglesias protestantes generaron un arraigo mayor. Al respecto, algunos autores señalan que las misiones católicas con los tobas obtuvieron fracasos sucesivos, probablemente a raíz del excesivo paternalismo y autoritarismo impuesto desde los reglamentos de las misiones (Martínez Sarasola, 1992). Por el contrario, el pentecostalismo resultó ser una de las vertientes de mayor crecimiento. (Wynarczyk y Semán, 1994), y gracias a su elasticidad ha sido apropiado por diversos grupos, dando lugar al fenómeno conocido como "pentecostalismo indígena" (Citro, 2009), como veremos más adelante. Los postulados de estos movimientos religiosos se apoyaron firmemente en la alfabetización, ya que su práctica se basaba en la lectura personalizada de la Biblia. Por tanto, la traducción de la Biblia a las lenguas indígenas, así como la alfabetización de posibles fieles era una de las principales acciones a desarrollar.

De este modo, las primeras propuestas de alfabetización para la población toba/qom se iniciaron en las iglesias evangélicas, ya que las misiones protestantes tenían como objetivo difundir la religión y promover la apropiación de la Biblia. Como vimos, estas acciones contrastaban con el contexto nacional/provincial marcado por una escolarización que no respetaba ni apreciaba las particularidades de las lenguas y culturas indígenas. En consecuencia, las iglesias evangélicas promovieron acciones para que la lengua nativa se materializara en el orden de la escritura (Wright, 2003) y por ende propiciaron espacios donde explorar nuevas herramientas de comunicación bilingüe, ya que la alfabetización incluía la lengua indígena y el español. Indudablemente, este proceso de alfabetización en lengua indígena supone una injerencia que no puede ser pensada sino como efecto de Estado, en la medida en que las iglesias pentecostales se ocupan de aspectos centrales de la instrucción académica y bilingüe de las poblaciones nativas. 
Ahora bien, en el caso de las poblaciones toba/qom, el vínculo con estas iglesias presenta una particularidad: la creación del Evangelio, movimiento socio-religioso que resume aspectos de las propuestas religiosas de los indígenas y del pentecostalismo. El proceso de creación del Evangelio en Chaco fue producto de diversas experiencias históricas regionales, atravesadas por divergencias y conflictos (Citro, 2009). Wright (1983) analiza el avance de la acción misionera evangélica en la región del Chaco y sostiene que este se dio en etapas sucesivas. La primera, entre 1816 y 1916, presentó principalmente iniciativas más bien individuales. Durante la segunda etapa, de 1916 a 1938, aparecieron acciones más organizadas y se asentaron las primeras iglesias pentecostales en la zona. A partir de 1938 y hasta 1945, el avance y la irrupción se masifican, haciéndose hincapié en la educación programática. Desde la década del cuarenta, a su vez, una serie de movimientos religiosos fueron liderados por aborígenes, como Pedro Martínez, en Chaco, y Luciano Córdoba, en Formosa.

Mediante este complejo proceso, se obtuvo el estatuto legal para la primera Iglesia Indígena Autónoma de la Argentina, llamada Iglesia Evangélica Unida. Su surgimiento fue influenciado por la labor de misioneros menonitas norteamericanos, que inicialmente establecieron una misión en Chaco y luego permanecieron en calidad de "asesores" u "obreros fraternales" (Ceriani y Citro, 2005). Según Altman y López (2011), estos misioneros luego de fallidos intentos de organizar misiones bajo la manera ortodoxa (lugares donde establecer y educar a los indígenas), a finales de los cincuenta transformaron la estrategia misional y se dedicaron exclusivamente a predicar, poniendo el acento en la comunicación en lengua indígena. Así, con su trabajo de acompañamiento y enseñanza de la Biblia, los "obreros fraternales" fueron actores fundamentales en la construcción del movimiento del Evangelio y en la sistematización de la lengua toba/qom (Altman y López, 2011) ${ }^{9}$.

9 Altman y López (2011) ponen de manifiesto el interés de ciertos sectores de las iglesias evangélicas en implementar modelos pedagógicos particulares: los círculos bíblicos, distinguiéndose de los más tradicionales "estudios bíblicos". Sucintamente se trató de espacios formativos más horizontales, con mayor énfasis en la oralidad que en la escritura, que implementaron los Obreros Fraternales Menonitas. 
En definitiva, el proceso de pasar de la oralidad a la escritura de la lengua toba/qom y la consecuente traducción de la Biblia fueron rasgos que distinguieron el accionar de los menonitas respecto de las otras congregaciones que intervenían en el Chaco (Wright, 2008). Misioneros emblemáticos, como la familia Buckwalter y Reyburn, consideraban que la lengua toba/qom era la vía para la evangelización y por eso fueron estudiosos de su gramática y le dieron su primer sistema para su escritura (Altman y López, 2011). Luego, en la década del setenta, Buckwalter junto al pastor toba/qom Orlando Sánchez se dedicaron a traducir capítulos de la Biblia y a escribir gacetillas religiosas. Este proceso tuvo un fuerte impacto en la lengua nativa por la estandarización de un particular sistema de escritura, que incluso se continúa utilizando en la actualidad; por hegemonizar una forma dialectal a partir de generalizar su escritura al resto, y por publicar los primeros textos escritos en lengua toba/qom.

\section{La región de las misiones}

A diferencia del caso anteriormente analizado, en Misiones la Iglesia católica mantuvo su influencia, aun con resistencias y conflictos, desde su llegada al territorio. La presencia de religiosos católicos a la zona del noreste de Argentina, sureste de Brasil y este del Paraguay fue muy temprana, por razones asociadas al proceso de conquista y colonización que detallamos en el inicio de este texto.

La dinámica más extendida en la zona fue el emplazamiento de reducciones misionales, de religiosos de la Compañia de Jesús, en las que los indígenas desarrollaban nuevas formas de vida. Como anticipamos, entre los intereses de los misioneros jesuitas se manifestaba una fuerte valoración de la lengua indígena: el guaraní. Los misioneros tuvieron un rol central en la consolidación de una escritura canonizada de esta lengua. La tarea dio lugar a la generación de una lengua particular, el llamado "guaraní estándar", hoy reconocida como lengua oficial del Estado paraguayo, pero que no se corresponde 
estrictamente con ninguna de las lenguas guaraníes indigenas (Meliá, 1968/1993).

Las transformaciones económicas y políticas de la región de Misiones tienen un punto de inflexión a comienzos del siglo XIX, cuando la economía de la provincia creció impulsada por la actividad rural, fundamentalmente de yerba mate, té y tabaco, en chacras y establecimientos agropecuarios. A diferencia del caso analizado anteriormente, en el que la población indígena fue incorporada como mano de obra útil y de bajo costo en las actividades de explotación económica de Chaco, en Misiones la población indígena se mantuvo relativamente al margen de las agroindustrias. La Ley Nacional de Colonización (1876) y la Ley de Ventas de Tierras Fiscales (1882) comenzaban a acelerar el proceso de colonización del Territorio Nacional de Misiones. La nueva legislación fue aprovechada para dar consistencia a este territorio de frontera estratégico. Las poblaciones indígenas se mantenían para entonces en el ambiente selvático, invisibilizadas.

En el plano educativo, luego de la expulsión jesuita no se registran propuestas formativas de la Iglesia católica para las poblaciones indígenas sino hasta la década de 1970. Por su parte, las políticas de escolarización estatales no repararon en la población indigena. Según pudimos registrar (Enriz, 2010), el acceso de poblaciones indígenas a la educación escolar se dio recién a partir de la década de 1970, de manera asistemática y dispersa, en escuelas estatales de distintos pueblos donde solo algunas familias incorporaban a sus hijos a la escolaridad común.

A fines de dicha década, se alojaron también escuelas de gestión privada y de práctica confesional católica en territorios de la población indígena, en el marco de un proyecto más general que abonaba la “aculturación programática” de las familias (Enriz, 2011).

El marco de esta propuesta fue el "Programa de Desarrollo Integral", acompañado por el Instituto Superior Antonio Ruiz de Montoya (ISPARM), de raigambre católica y financiado por el gobierno nacional. La propuesta intervenía sobre la estructura organizativa: 
generaba espacios análogos a las reducciones, con viviendas consolidadas y territorios cercados; buscaba "posibilitar la paulatina integración de los aborígenes en el proceso de desarrollo provincial favoreciendo la participación de los mismos" (Acción de gobierno 19761983); se proponía facilitar la inclusión en el mercado y la formación para esta participación.

A las propuestas de tipo productivo se sumó una escuela de jornada completa con comedor escolar perteneciente a la gestión privada ${ }^{10}$, vinculada al Obispado, que incluyó las viviendas necesarias para representantes eclesiásticos y docentes.

Para la misma época, escuelas de gestión pública ubicadas estratégicamente comenzaron a recibir población indígena. No había una propuesta escolar particular, pero sí se daban los primeros acercamientos del Estado, generando escuelas en zonas en las que habitaban masivamente familias indígenas. En algunos casos, de modo artesanal, la presencia de religiosas de distintas órdenes católicas se puso a disposición de esta política. Las religiosas ingresaban a los cargos públicos por concurso regular, llevadas especialmente por su interés de trabajar con población indígena.

En resumen, las propuestas de mediados de la década de 1970 se correspondieron en varios sentidos con las propuestas reduccionales, en primer lugar, porque persiguieron el objetivo de sedentarizar y de evangelizar. Luego, porque también pusieron el énfasis en la formación de los niños, la inclusión de los adultos en el sistema capitalista, la producción de una espacialidad condicionada e incluso el establecimiento de núcleos familiares con lógicas no indígenas. Esta propuesta de reduccional moderna llegaria a nuevos sujetos, a poblaciones que no habían accedido a la fe católica aún.

10 En Argentina existe una modalidad de financiamiento educativo que se denomina gestión privada. La misma supone que el Estado reconoce los gastos permanentes de una institución educativa que no fundó, pero que considera necesaria. Como no la fundó el Estado, la institución no le pertenece, pero la financia y monitorea. Esta, por su parte, se encuentra obligada a brindar los conocimientos curriculares mínimos, pero puede agregar otros, por ejemplo, religión. 


\section{Educación Intercultural Bilingüe: experiencias contemporáneas}

Tal como desarrollamos en los apartados anteriores, muchos de los espacios de socialización y escolarización en contextos comunitarios indígenas fueron impulsados por organizaciones vinculadas a la transformación política, social y/o religiosa de la sociedad (Almirón et al., 2013). Estas eran experiencias de bilingüismo y alfabetización en lengua indígena (aunque también de castellanización) que, si bien han constituido antecedentes ineludibles de la institucionalización de una perspectiva escolar intercultural, se sostuvieron como iniciativas informales y paralelas a la educación oficial, sustituyendo en ocasiones la oferta pública. La concepción de que otras fuerzas institucionales pueden ocupar los roles que el Estado no logra desempeñar en materia educativa, se inició con aquellas primeras tareas de los misioneros. Esta misma lógica pervive actualmente en el sistema educativo: alli donde el Estado no logre anclar un establecimiento escolar, pueden hacerlo instituciones confesionales (y otros privados) y luego solicitar al Estado el reconocimiento y sostenimiento económico de dicho proyecto ${ }^{11}$.

Como expresamos en el inicio de este artículo, las propuestas educativas interculturales llegan a la población indigena recientemente, ya que la experiencia previa se caracterizó por jerarquizar la incorporación del castellano, las religiones europeas y las prácticas laborales capitalistas. La propuesta intercultural, que contempla la lengua indígena, así como otros aspectos de la cultura de estos pueblos, se implementa en Chaco desde fines de los ochenta, y en Misiones hace una década. En el primer caso, como resultado de las demandas indígenas por una educación inclusiva que contemple el bilingüismo y los saberes propios de las comunidades a partir de incluir a un docente indígena en las aulas. En el otro, como corolario de una propuesta de escolaridad de frontera cuyo objetivo principal era deslindar el castellano y el portugués, y como consecuencia de la demanda de los propios docentes que se encontraban trabajando con población

\footnotetext{
11 Se conoce a este sistema como de subvenciones. El Estado se hace cargo de los salarios del personal docente y no docente. Una importante proporción de los casos de escuelas confesionales están ubicados en zonas en las que "compiten" con escuelas públicas, laicas, gratuitas. Estas instituciones están habilitadas para cobrar cuotas a sus alumnos.
} 
indígena, la cual dio inicio a un proyecto de incorporación de auxiliares bilingües (tal es la denominación que recibieron) a las aulas. Más allá de las particularidades de Chaco y Misiones, en ambos casos los auxiliares bilingües son indígenas elegidos por sus comunidades, que, tomando un taller de capacitación, se incorporan al plantel escolar para desempeñarse como docentes.

Las experiencias concretas se desarrollan siguiendo algunos esquemas comunes. En algunos casos su tarea se lleva a cabo como pareja pedagógica de un maestro no indígena; en otros, tienen sus horas particulares. La mayoria de los primeros docentes no indigenas, que se desempeñaban en escuelas para indígenas, provenían del ámbito religioso; en algunos casos tenían nociones de lectoescritura en la lengua indígena.

En la actualidad, la alfabetización se desarrolla en castellano, pero suele implementarse una materia de "cultura y lengua", en la que los auxiliares bilingües desarrollan los conocimientos que consideran relevantes. En la selección de los mismos, así como en otros aspectos de la enseñanza, la comunidad a través de sus representantes y especialmente de las figuras de autoridad tiene un rol central. En el caso de Misiones se destaca el rol del opygua (líder espiritual) como evaluador de dicha asignatura (Enriz, 2010), mientras que en Chaco se encarga de esta tarea el Consejo de Ancianos (Medina y Hecht, 2015).

\section{Comentarios finales}

Tempranamente, la escolaridad estatal en Argentina se propuso abarcar, con una propuesta monolítica que daba cuenta de los intereses y perspectivas de los sectores hegemónicos, a un amplio porcentaje de población, que, en términos generales, excluía sin embargo a los indígenas, arrinconados en los márgenes de las fronteras internas del territorio conformado como nacional. A esta propuesta la antecedian diversas acciones de iglesias, que sí se proponían trabajar en la alfabetización, castellanización y evangelización de las poblaciones 
indígenas. La distancia entre ambas propuestas no es solo temporal: mientras las primeras acciones formativas de las iglesias privilegiaron el trabajo con indígenas, y, en su afán por lograr evangelizarlos, se dedicaron a conocer aspectos de la cultura de estos pueblos, las propuestas estatales se pensaron y desarrollaron a espaldas de los pueblos indígenas. Si bien muy recientemente, en las últimas tres décadas, se ha dado un espacio para incluir a la diversidad socioétnica de nuestro territorio en el sistema escolar, esta apertura se produce desde un marco general de subordinación de saberes y conocimientos.

En este texto hemos discutido la compleja, desigual y tardía inclusión de la voz y perspectiva indígenas en las propuestas generadas desde el propio Estado nacional, contrastando ese accionar con el de otros actores, como las iglesias, que dieron cuenta muy tempranamente del valor de las lenguas indígenas y la relevancia de la cuestión formativa indigena, aunque persiguiendo objetivos propios.

Las iglesias han desarrollado programas educativos desde tiempos muy pretéritos (antes de la existencia del propio Estado), con propuestas pedagógicas diferenciadas y con objetivos múltiples: la sedentarización, la evangelización, la estandarización y escrituración de las lenguas nativas, la alfabetización, la inclusión como fuerza militar del Estado o bien como fuerza de trabajo. Vimos en este escrito la multiplicidad de acciones llevadas a cabo, la búsqueda de caminos pedagógicos, el interés por conocer la lengua y cultura de los indigenas en el marco de los programas evangelizadores y, especialmente, la inclusión de indígenas en estas tareas. A su vez, destacamos el rol que las iglesias otorgaban a los niños y niñas en las tareas de difusión y profusión de los saberes, conocimientos y prácticas difundidas por estas. Consideramos que las actuales politicas de EIB mantienen un fuerte énfasis en la niñez, como momento formativo privilegiado a la hora de producir un acercamiento a aspectos culturales considerados como "otros": otra lengua, otra religión, otras formas de expresión y comunicación. Haber documentado estos intereses a lo largo del tiempo, nos permite acercarnos a los procesos actuales y ver en ellos las huellas de estos procesos pasados, comprendiendo estas complejas dinámicas ahora desde un presente historizado (Rockwell, 2009). 
Las relaciones que las poblaciones indígenas desarrollaron y desarrollan con diversas agencias representan un interesante ámbito donde reflexionar en torno a los efectos de Estado (Trouillot, 2001), en tanto instancias en las que los intereses estatales son representados o llevados a cabo por otros actores. En primer lugar, resulta interesante tener en cuenta que las normas locales que amparan a los grupos indígenas se anclan en una normativa internacional que es considerada de mayor rango, el Convenio 169 de la OIT. Frente a la vulneración de derechos indígenas, en la mayoría de las ocasiones se recurre primero a esta normativa internacional que trasciende los límites del Estado nación. Por otro lado, un sinnúmero de organizaciones internacionales (entre ellas, las iglesias tal como hemos analizado aqui) han tenido a las poblaciones indigenas locales como su principal foco de acciones. Finalmente, la relación de estas poblaciones con el Estado se ve atravesada, además, por un internacionalismo que las vincula fuertemente a otros países del continente, pues sus organizaciones y contactos anteceden y trascienden los límites territoriales impuestos por el Estado.

En cualquier caso, consideramos que el rol de las iglesias es clave en los procesos escolarizadores indígenas en Argentina y que, aún hoy, genera efectos de Estado, así como también lo hacen en la actualidad otros actores de la sociedad civil. En las experiencias analizadas pudimos trazar un recorrido de acciones, valoraciones y relaciones sociales que marcan una continuidad de tres siglos de prácticas de las iglesias respecto de la escolarización indígena.

También pudimos expresar el rol activo de las poblaciones indígenas en un proceso que en algunos casos dio origen a nuevas iglesias, en otros mostró el rechazo por algunos credos o la falta de permeabilidad de las ideas religiosas en ciertos grupos. Así mismo, quedó manifestado que los procesos evangelizadores pudieron ser rechazados por ciertos grupos, por vía del éxodo o bien por la indiferencia. Esta asociación diferencial entre grupos y religiones/iglesias específicas evidencia el rol de las poblaciones indígenas frente a las misiones y sus posibilidades de acción. 
Hemos visto también que las propuestas escolarizadoras de las iglesias para poblaciones indígenas fueron muy tenaces en la búsqueda de propuestas pedagógicas particulares, que permitieran atraer el interés de estas poblaciones especialmente. El actual reclamo docente de más capacitaciones, ámbitos de formación específicos y dinámicas escolares particulares parece hacerse eco de aquella búsqueda tan sistemática de los misioneros.

En unos y otros casos, los ámbitos formativos que las propias comunidades utilizan para sí mismas se han mantenido como una incógnita. Las propuestas no han recabado nunca en los ámbitos existentes, los que los propios grupos utilizan para dinamizar su cultura cotidianamente, generando nuevos espacios y modalidades de intercambio. La brecha entre unos y otros permitió a algunos miembros de las comunidades discurrir por ambos carriles, en un imbricado proceso de identificación.



Figura 1. Mapa de pueblos indígenas en Argentina Fuente: Ministerio de Educación de la Nación 


\section{Referencias}

Achilli, E. (2013). Investigación socioantropológica en educación. Para pensar la noción de contexto. En N. Elichiry (Comp.), Historia y vida cotidiana en educación. Perspectivas interdisciplinarias (33-47). Buenos Aires: Manantial.

Almirón, V. S., Artieda, T. y Padawer, A. (2013, julio). Acciones de alfabetización en comunidades indígenas qom y wichí del Chaco (1964-1973). En X RAM "Situar, actuar e imaginar antropologías desde el Cono Sur". X Reunión de Antropología del Mercosur, organizada por la Universidad Nacional de Córdoba, Argentina.

Altman, A. y López, A. (2011). Círculos bíblicos entre los aborígenes chaqueños: de la utopía cristiana a la necesidad de legitimación. Sociedad y religión, 21, 34-35.

Artieda, T. y Hecht, A. C. (2012). El tratamiento de lo indigena en los estudios de Historia de la Educación en la Argentina. Diálogos con la Antropología. En XVII Jornadas Argentinas de Historia de la Educación. Congreso organizado por la Universidad Nacional de Tucumán, Argentina.

Artieda, T. y Rosso, L. (2005). Propuestas educativas para aborígenes del norte argentino en las fases del proceso de proletarización. 1884-1922. En A. Ascolani (Comp.), El sistema educativo en Argentina. Nuevas perspectivas históricas (pp. 70-87). Rosario: Laborde editor.

Avellaneda, M. y Qualerli, L. (2007, junio). Las milicias guaranies en el Paraguay y Río de la Plata: alcances y limitaciones (1649-1756). Estudos Ibero-Americanos, XXXIII(1), 109-132.

Borton, A., Enriz, N., García Palacios, M. y Hecht, A. C. (2010). Una aproximación a las representaciones escolares sobre el niño indígena como sujeto de aprendizaje. En S. Hirsch y A. Serrudo (Comps.), La Educación Intercultural Bilingüe en Argentina. Identidades, lenguas y protagonistas (pp. 197-222). Buenos Aires: Novedades Educativas. 
Braunstein, J. y Miller, E. (1999). Ethnohistorical Introduction. En E. Miller (Ed.), Peoples of the Gran Chaco. Native Peoples of the Americas (pp.1-22). West Port, CT: Bergin \& Garvey.

Ceriani, C. y Citro, S. (2005). El movimiento del evangelio entre los tobas del Chaco argentino. Una revisión histórica y etnográfica. En B. Guerrero Jiménez (Ed.), De indio a hermano. Pentecostalismo indigena en América Latina (pp. 111 170). Chile: Ediciones Campvs.

Citro, S. (2009). Cuerpos significantes: travesias de una etnografia dialéctica. Buenos Aires: Editorial Biblos.

Díaz, S. (2000). El niño indígena como agente de evangelización en las reducciones jesuíticas de guaraníes. En III Congreso Argentino de Americanistas, Año 1999, Buenos Aires, Argentina.

Enriz, N. (2010). Un sueño blanco, reflexiones sobre la educación Mbyá guaraní en Argentina. Revista Amazónica, 2(1), 24-37.

Enriz, N. (2011). Jeroky Porã. Juegos, saberes y experiencias infantiles Mbyá guaraní en Misiones. Alemania: Lincom Studies in Anthropology 14.

Esquivel, J. C. (2008). Laicidad en los márgenes: historia de la presencia pública de la Iglesia católica en Argentina y Brasil. En G. Liendo, V. Barrientos y M. Huaco (Comps.), Memorias del Primer Seminario Internacional Fomentando el conocimiento de las libertades laicas. Lima, Perú.

García Palacios, M. (2012). Religión y etnicidad en las experiencias formativas de los niños y niñas de un barrio toba de Buenos Aires (Tesis de Doctorado en Antropología Social). Universidad de Buenos Aires, Buenos Aires.

García Palacios, M., Hecht, A. C. y Enriz, N. (2015). Pueblos indígenas y escolarización: los usos del concepto de interculturalidad en el debate educativo contemporáneo. Revista Educación, lenguaje y sociedad, 12(12), 53-78. 
Giordano, M. (2004). Itinerario de imágenes del indígena chaqueño. Del Territorio Indio del Norte al Territorio Nacional y Provincia del Chaco. Anuario de Estudios Americanos, LXI(2), 517-550.

Gordillo, G. (2006). En el Gran Chaco. Antropología e Historias. Buenos Aires: Prometeo.

Hecht, A. C. (2007). Pueblos indigenas y escuela. Politicas homogeneizadoras y políticas focalizadas en la educación argentina. Políticas Educativas, 1(1), 183-194.

Hecht, A. C., García Palacios, M., Enriz, N. y Diez, M. L. (2015). Interculturalidad y educación en Argentina: reflexiones a propósito de un concepto polisémico. En G. Novaro, A. Padawer y A.C. Hecht (Comps.), Educación, pueblos indigenas y migrantes. Avances desde México, Brasil, Bolivia, Argentina y España (pp. 43-64). Buenos Aires: Biblos.

Hirsch, S. y Serrudo, A. (2010). La Educación Intercultural Bilingüe en Argentina. Identidades, lenguas y protagonistas. Buenos Aires: Noveduc.

INDEC. (2010). Censo Nacional de Población. Argentina.

Iñigo Carrera, N. (1983). Campañas militares y clase obrera, Chaco 1870-1930, Serie Historia Testimonial 25. Buenos Aires: CEAL.

Martínez Sarasola, C. (1992). Nuestros paisanos los indios. Buenos Aires: Emecé.

Medina, M. y Hecht, A. C. (2015). Debates en torno a la Ley de Educación Pública de Gestión Comunitaria Bilingüe Intercultural Indígena en Chaco. Praxis Educativa, 19(2), 34-42.

Melià, B. (1968/1993). El guaraní conquistado y reducido. Asunción: Biblioteca Paraguaya de Antropología, Universidad Católica.

Neufeld, M. R. y Thisted, J. A. (1999). "Vino viejo en odres nuevos": acerca de educabilidad y resiliencia. Cuadernos de Antropología Social, 19, 83-99. 
Novaro, G. (2003). "Indios", “aborígenes" y "pueblos originarios". Sobre el cambio de conceptos y la continuidad de las concepciones escolares. Revista Educación, lenguaje y sociedad, I(1), 199-219.

Padawer, A., Artieda, T., Borton, L. y Almirón, V. S. (En prensa). Alfabetización y evangelización: una mirada comparada acerca de propuestas educativas hacia los qom en el marco de congregaciones religiosas. En L. Cerletti, G. Novaro, A. Padawer y L. Santillán (Comps.), Experiencias formativas, procesos de identificación y regulación social de la infancia. Buenos Aires: Editorial Biblos.

Priore, M. del. (1991). O papel branco, a infancia e os jesuitas na colonia. En M. Del Priore (Org.), Historia da crianza no Brasil (pp. 10-27). Brasil: Ed. Contexto.

Puiggrós, A. (2006). Historia de la educación argentina: sujetos, disciplina y curriculum en los orígenes del sistema educativo argentino (1885-1916), Tomo 1. Buenos Aires: Galerna.

Rockwell, E. (2009). La experiencia etnográfica. Historia y cultura en los procesos educativos. Buenos Aires: Paidós.

Roulet, F. (1993). La resistencia de los guaraní del Paraguay a la conquista española (1537-1556). Posadas: Editorial Universitaria, Universidad Nacional de Misiones.

Szulc, A. (2009, julio). "No podía seguir en dos iglesias". Encrucijadas identitarias en clave religiosa en torno a niños mapuche del Neuquén. $53^{\circ}$ Congreso de Americanistas. Centro histórico de la ciudad de México.

Tamagno, L. (2001). Nam Qom Hueta'a na Doqshi Lma'. Los tobas en la casa del hombre blanco. Identidad, Memoria y Utopía. La Plata: Ediciones Al Margen.

Trouillot, M. R. (2001). The Anthropology of the State in the Age of Globalization: Close Encounters of the Deceptive Kind. Current Anthropology, 42(1), 125-138.

Wilde, G. (2009). Religión y poder en las misiones de guaranies. Buenos Aires: SB Editora. 
Wolf, E. (2014). Europa y la gente sin historia. México: Fondo de Cultura Económica.

Wright, P. (1983). Presencia protestante entre aborígenes del Chaco argentino. Scripta Ethnologica Supplementa, VII, 73-84.

Wright, P. (2003). Colonización del espacio, el cuerpo y la palabra en el Chaco argentino. Horizontes Antropológicos, 9(19), 137-152.

Wright, P. (2008). Ser en el sueño. Crónicas de historia y vida toba. Buenos Aires: Editorial Biblos.

Wynarczyk, H. y Semán, P. (1994). Campo evangélico y pentecostalismo en la Argentina. En A. Frigerio (Comp.), El pentecostalismo en la Argentina (pp. $37-$ 54). Buenos Aires: CEAL.

\section{Cómo citar este artículo}

Enriz, N., García Palacios, M. y Hecht, A. C. (2017). Llevar La palabra. Un análisis de la relación entre las iglesias y la escolarización de niños indígenas tobas/qom y mbya-guarani de Argentina. Universitas Humanística, 83, 187 212. http://dx.doi.org/10.11144/Javeriana.uh83.lpar 